\title{
Comparison of different tracers for PIV measurements in EHD airflow
}

\author{
M. HAMDI ${ }^{\mathrm{a}}$, M. HAVET ${ }^{\mathrm{a}}$, O. ROUAUD ${ }^{\mathrm{a}}$, D. TARLET ${ }^{\mathrm{b}}$
}

Key-words: Electrohydrodynamics, corona discharge, PIV, tracer particles.

\begin{abstract}
In this study, a proposed method for selecting a tracer for PIV measurement in EHD flows was developed. To begin with, several published studies were identified that exploit different tracers; such as oil smoke, cigarette smoke, and $\mathrm{TiO}_{2}$. An assortment of tracers was then selected based on comparisons with conventional dimensionless numbers; Stokes number (St), Archimedes number (Ar) and electrical mobility ratio (M). Subsequently, an experimental study for testing tracers was developed, which enabled the velocity profile of an ionic wind generated by a needle/ring configuration to be measured. Air velocity measurements carried out with a Pitot tube, considered as the reference measurements, were compared to PIV measurements for each tracer. In addition, the current-voltage curves and the evolution of the current during seeding were measured. All the experimental results show that $\mathrm{TiO}_{2}, \mathrm{SiO}_{2}$ microballoons and incense smoke are the ideal tracers in the series of tracers investigated.
\end{abstract}

M. HAMDI, M. HAVET, O. ROUAUD,

LUNAM, ONIRIS, GEPEA (CNRS UMR 6144), rue de la

Geraudière, BP 82225, 44322 Nantes, France

\section{TARLET}

LUNAM, Polytech Nantes, Laboratoire de

Thermocinétique de Nantes (CNRS UMR 6607),

rue C. Pauc, BP 50609, 44306 Nantes, France

\section{List of symbols}


$\tau_{p}$ Relaxation time of particle (s or $\mu \mathrm{s}$ )

$\tau_{f}$ Characteristic time of fluid (s or $\mu \mathrm{s}$ )

$d$ Particle diameter $(\mu \mathrm{m}$ or $\mathrm{m})$

$\mu$ Dynamic viscosity (Pa.s)

Characteristic velocity $L$ Characteristic length (m)

$\rho$ Density $\left(\mathrm{kg} \cdot \mathrm{m}^{-3}\right)$

$g$ Gravity (m.s $\left.{ }^{-2}\right)$

Cc Cunningham coefficient

$E$ Electric field strength $\left(\mathrm{kV} . \mathrm{m}^{-1}\right)$

$K$ Electrical mobility $\left(\mathrm{m}^{2} \cdot \mathrm{V}^{-1} \cdot \mathrm{s}^{-1}\right)$

$n$ Number of charges

$X^{s}$ Specific humidity $\left(\mathrm{kg} \cdot \mathrm{kg}^{-1}\right)$

RH Relative humidity (\%)

$P_{\text {atm }}$ Atmospheric pressure $(\mathrm{Pa})$

$T_{a m b}$ Ambient temperature (K)

$e$ Elementary electron charge $\left(1.6 \times 10^{-19} \mathrm{C}\right)$

$R_{p}$ Radius (m)

$\delta$ Relative density of the air

\section{Subscript}

$f$ Fluid

p Particle

L Limit

in Internal

ex External
$D_{n}$ Diameter of the needle $(\mathrm{mm})$

$\epsilon \quad$ Dielectric constant of free space (F.m $\left.{ }^{-1}\right)$

$\epsilon_{p}$ Relative dielectric constant of particle

$\lambda$ Mean free path $(\mu \mathrm{m})$

$K_{e} \quad$ Relativity constant $\left(9 \times 10^{9}\right)$

$N_{i}$ Ion concentration (ions. $\mathrm{m}^{-3}$ )

$Z_{i}$ Ion mobility $\left(\mathrm{m}^{2} \cdot \mathrm{V}^{-1} \cdot \mathrm{s}^{-1}\right)$

$\gamma$ Surface tension $\left(\mathrm{N} . \mathrm{m}^{-1}\right)$

I Intensity of electric current $(\mu \mathrm{A})$

$V$ Voltage (V or $\mathrm{kV})$

$r$ Cylinder radius $(\mathrm{mm})$

$y$ Distance from the exit jet (mm)

$L_{c}$ Characteristic length (m)

$m$ Surface roughness

$U_{y}$ Velocity along $y$ axis $\left(\mathrm{m} . \mathrm{s}^{-1}\right)$

$U_{c}$ Characteristic velocity $\left(\mathrm{m} \mathrm{s}^{-1}\right)$ 


\section{Introduction}

Electrohydrodynamics (EHD) is a branch of fluid mechanics concerned with electrical force effects. EHD phenomena are already widely used in many processes such as the collection of fine particles in electrostatic precipitators (ESP) or ozone production (Kawamoto and Umezu (2008)). They are also of great interest for the enhancement of heat and mass transfer. Allen and Karayiannis (1995) mentioned that one of the major ways in which EHD can improve single phase convective heat transfer is by the flow of a "corona wind", or an "ionic wind". The electric forces generate secondary flows, alter the boundary layer structure and may increase the convective heat and mass transfer coefficients. Numerous works have dealt with this innovative technique, especially for improving the heat and mass transfer of the drying process (Shimamoto et al. (2004), Wangnipparnto et al. (2002), Ould Ahmedou and Havet (2009)).

The investigation and optimization of EHD processes require detailed knowledge and control of secondary flows. In recent years, researchers have become increasingly interested in imaging measurement techniques for the characterization and analysis of EHD flow patterns. The most recent studies that use PIV and LDV methods have been performed to characterize the ionic wind produced by surface dielectric barrier discharge plasma actuators (Neumann et al (2013) Debien et al (2012), Zouzou et al. (2011), Moreau (2007), Joussot et al (2013)) and in the field of particle collection in electrostatic precipitators (Niewulis et al,2009, Chang JS et al, 2005).

Particle Imaging Velocimetry (PIV) requires the introduction of seeding particles into the fluid, which are assumed to follow the fluid's motion. For gas flow, the mapping of the flow structure using tracer particles is more critical, since the particle density is usually several orders of magnitude higher than the density of the gas. The main difficulty in the use of 2D and 3D PIV visualization techniques in air is related to the control of the seeding particles; they have to remain a passive tracer and reproduce the vortex structures of air. The apparent velocity of the particles at any point in space should be the same as the fluid in which they are immersed.

Tracer particles used in PIV have been widely studied by Melling (1997). Ikeda et al. (1994) used tracers named " $\mathrm{SiO}_{2}$ microballoons" with a low density. Pol and Balakumar (2012) used plastic particles of Expancel microspheres (EMS) for PTV measurements in air; their density is 10 times lower than that of oil. Metal tracers like particles of $\mathrm{AlO}_{3}$ were used by Paone et al. (1996), $\mathrm{SiO}_{2}$ by Willert and Jarius (2002), $\mathrm{TiO}_{2}$ and $\mathrm{ZrO}_{2}$ by Reuss et al. (1989).

In the presence of an electric field of a few $\mathrm{kV} . \mathrm{cm}^{-1}$, the choice of the tracer is more complicated as the electric field may affect tracer behavior. Although sometimes mentioned, the influence of electrical forces is systematically neglected in most studies. According to Hinds (1999), in aerosol mechanics, the most important electrostatic effect is the force exerted on a charged particle in an electrostatic field. Most aerosol particles carry some electric charge, and some may be highly charged. For highly charged particles, the electrostatic force can be thousands of times greater than the gravitational force and may cause the seeding particles to deviate from the bulk fluid flow, thus skewing the PIV measurements (Balagopal and Go (2011)). In the case of EHD flows, the influence of electric forces is not negligible and must be considered (Atten et al. (1989) and Kallio and Stock (1992)). Moghaddam et al. (2006), who used glass microspheres for Laser Doppler Velocimetry (LDV) measurements, demonstrated that the measurement should be corrected by the slip velocity. As this latter requires a multiphysics modeling approach, the methodology cannot be recommended.

There have been several different types of tracers used in studies involving EHD flows. Cigarette smoke, used by Mizeraczyck et al. (2003), had a diameter less than $1 \mu \mathrm{m}$. Balagopal and Go (2011) and Zouzou et al. (2011) used an incense stick to generate seeding particles. Solid particles of $\mathrm{TiO}_{2}$ with a diameter less than $1 \mu \mathrm{m}$ were used by Podlinski et al (2005) for PIV measurements in electrostatic precipitators for dust particle collection. Recently, Kriegseis et al (2012) used Di-Ethyl-Hexyl-Sebacat (DEHS) aerosol 
with particles having a mean diameter of $0.9 \mu \mathrm{m}$. Béquin et al. (2003) used a fog generator based on water condensation to provide seeding particles for LDV measurements in an EHD flow.

Léger et al. (2001) presented a study using oil drops, without specifying the procedure for particle diameter measurement. Ullum et al. (2004) used olive oil for PIV 3D. Joussot et al (2013) used olive oil droplets produced by an aerosol generator to perform 3C LDV system in a box. The diameter of the droplets was around $1 \mu \mathrm{m}$. Kotsonis and Ghaemi (2012), for investigations in plasma actuators with PIV, used also olive oil as a seeding particle in a Plexiglas box generated by TSI atomizer (mean diameter of 1 $\mu \mathrm{m})$. It was found that particle accumulation near the wall could introduce errors. To avoid this, forced mixing through an air blower was introduced before the measurements to insure the homogeneity of the seeding particles. The dielectric Odina oil droplets with mean diameter of about $0.3 \mu \mathrm{m}$ was used as seeding particles to measure the velocity with LDV and PIV systems in the investigations conducted by Benard and Moreau (2010), and Benard et al (2013). By referring to Chang et al (2004), the authors sited that the small size of these particles ensure that accurately follows the overall flow field since the charged effects can be neglected.

Despite the great number of works dealing with velocity measurements using optical techniques, it can be noted that the selection of the tracer is not greatly explored. In this work, a procedure for selecting the optimal tracer is studied in the case of an EHD flow utilizing a needle/ring electrode. This configuration has been studied by Rickard et al. (2005), the tracers were seeded downstream of the electrodes to avoid the possibility of tracer charging. As a first step, dimensionless criteria are proposed and tracers are classified according to these parameters. Secondly, the theoretical analysis is reinforced by an experimental study. The velocity profile at the exit of a jet generated by an ionic wind is measured within the needle/ring configuration. PIV measurements with different tracers are compared to a reference measurement performed without a tracer (Pitot tube). In addition, other technical points are discussed such as the evolution of the current during seeding.

\section{Tracking indicators}

Based on a literature review, seeding particles for an EHD flow must satisfy the following conditions:

1. Their size should be as small as possible so that it does not affect the mechanical properties of the fluid, but large enough to be visible on the camera images (Vincent (2007) and Béquin et al. (2003)).

2. Their size and density should fulfill conditions avoiding sedimentation and inertial effects (Tarlet et al. (2011)).

3. They must have certain physical characteristics in order to avoid charge and polarization phenomena and interaction with the electric field (Hinds (1999)).

Table 1 summarizes some tracer particles used in different fields of imaging measurement techniques (PIV, LDV) for EHD in air. In general, particle diameter and density are given but there is a lack of information about their electrical properties.

Table 1 Tracers found in the literature for imaging measurement techniques in EHD

\begin{tabular}{|l|l|c|c|c|}
\hline Publication & Tracer & $\begin{array}{c}\text { Mean } \\
\text { diameter }(\mu \mathrm{m})\end{array}$ & $\begin{array}{c}\text { Density } \\
\left(\mathrm{kg} . \mathrm{m}^{-3}\right)\end{array}$ & $\begin{array}{c}\text { Application } \\
\text { in EHD }\end{array}$ \\
\hline Léger et al. (2000) & Oil smoke & 0.3 & - & PIV \\
\hline Chang et al. (2005) & $\mathrm{TiO}_{2}$ & 0.2 & - & PIV \\
Podlinslki et al (2005) & $\mathrm{TiO}_{2}$ & $<1$ & - & PIV \\
\hline Balagopal (2011) & Incense & 1 & 1100 & PIV 3D \\
\hline Niewulis et al. (2009) & Cigarette smoke & $<1$ & - & PIV 3D \\
\hline Ullum et al. (2004) & Olive oil smoke & $0.5-2$ & 900 & \\
\hline
\end{tabular}




\begin{tabular}{|l|l|c|c|c|}
\hline $\begin{array}{l}\text { Moghaddam et al. } \\
(2006)\end{array}$ & $\begin{array}{l}\text { Glass microspheres } \\
\text { Polystyrene nanospheres }\end{array}$ & $\begin{array}{c}2.5 \\
0.5\end{array}$ & - & $\begin{array}{c}\text { LDV } \\
\text { LDV }\end{array}$ \\
\hline $\begin{array}{l}\text { Kotsonis and Ghaemi } \\
(2011)\end{array}$ & Olive oil & 1 & - & PIV \\
\hline Kriegseis et al (2012) & (DEHS) aerosol & 0.9 & - & PIV \\
\hline Joussot et al (2013) & Olive oil smoke & 1 & - & LDV \\
\hline Benard et al (2013) & Dielectric oil (Odina919) & 0.3 & - & PIV \\
\hline
\end{tabular}

As mentioned by Vincent (2007), some indicators have to be defined in order to quantify the ability of tracers to follow the flow.

The Stokes number $S t$ is widely recognized as an indicator for traceability of particles (Kallio and Stock (1992) and (Vincent (2007)) (Eq. (1)):

$$
S t=\frac{\tau_{p}}{\tau_{f}}=\frac{\tau_{p} U_{c}}{L_{c}}=\frac{\rho_{p} d_{p}^{2} U_{c} C c}{18 \mu_{f} L}
$$

The Stokes number is defined as the ratio of two characteristic times:

1) The relaxation time of the particle:

2) The characteristic time of the carrier fluid:

$$
\tau_{p}=\frac{\rho_{p} d_{p}^{2}}{18 \mu_{f}}
$$

$$
\tau_{f}=\frac{L_{c}}{U_{c}}
$$

Eq. (1) shows the importance of the product $\rho_{p} d_{p}^{2}$, and takes into account the slippage with the Cunningham factor $C c$. This sliding effect is due to a velocity which is not equal to zero at the surface of the particles, when their size becomes too small. The Cunningham factor $C c$ (Eq. (2)) is equal to 1.15 for particles of $d_{p}=1 \mu \mathrm{m}$. (Hinds (1999)).

$$
C c=1+\frac{\lambda}{d}\left(2514+0.8 \times \exp \left(-0.55 \times \frac{\lambda}{d}\right)\right)
$$

The relaxation time can be used as a direct measurement of the deviation of the tracer particle from the flow direction, thus the Stokes number gives an indication of the ability of a specific particle to track the flow. For low St, the particle tends to closely follow the motion of the surrounding air as it changes direction. Alternatively, for large St, the particle does not respond to abrupt changes in air movement. According to Kallio and Stock (1992), the tracer particle is suitable when the Stokes number $S t \ll 1$. Recently, Tarlet et al. (2011) and Burgmann et al. (2001) reported that for a Stokes number $S t \leq 10^{-3}$, the deviation of the tracer particle is negligible.

The Archimedes number, $A r$ (Eq. (3)), expresses the effects of buoyancy on the particles. If $A r \rightarrow 0$, the particle is not influenced by buoyancy. For $A r<5 \times 10^{-2}$, tracer particles are not, or only slightly, affected by sedimentation phenomena (Tarlet et al. (2011)).

$$
A r=\frac{g d_{p}^{3} \rho\left(\rho_{p}-\rho_{f}\right)}{\mu_{f}^{2}}
$$

Atten et al. (1989) introduced the parameter M (also called EHD "Mobility ratio" (IEEE -DEIS-EHD technical committee (2003)), which defines the relationship between the mobility of gas molecules and the mobility of particles in the gas in the presence of an electric field (Eq. 4). 


$$
M=\frac{\left(\frac{\epsilon_{f}}{\rho_{f}}\right)^{\frac{1}{2}}}{K}
$$

The mobility ratio is thus the ratio of:

1) The air mobility equivalent under the effect of the electric field

2) The particle mobility $K$ under the effect of the electric field

This ratio can be understood as the ratio of the characteristic velocity of the fluid to the migration rate of electrically charged ions (ionic drift velocity). Atten et al. (1989) gave the M parameter a transition value equal to 3 .

- For $\mathrm{M} \gg$ > 3, there is a strong drive of the charged particles by the fluid, rather than by the electric field. This is the appropriate situation for measurements.

- For $\mathrm{M} \ll<3$, the fluid has little effect on the particles, compared to the effect of the electric field.

The electrical mobility of a particle $K$ expresses its ability to move in an electric field. It is formulated as follows (Eq. (5)), where $n$ is the number of charges carried by the particle and $e$ is the elementary charge. This formula is valid for a Reynolds number of a particle $\operatorname{Re}_{\mathrm{p}}<1$.

$$
K=\frac{n e C c}{3 \pi \mu_{f} d_{p}}
$$

According to Hinds (1999), in the case of corona discharge, the charging mechanism is presumed to be the dominant one, and the number of charges $n$ acquired by a particle during a time $t$ in an electric field with an ion number concentration $N i$ is expressed as follows (Eq. (6)).

$$
n(t)=\left(\frac{3 \epsilon_{p}}{\epsilon_{p}+2}\right)\left(\frac{E d_{p}^{2}}{4 K_{e} e}\right)\left(\frac{1+K_{e} e N_{i} Z_{i} t}{1+\pi K_{e} e N_{i} Z_{i} t}\right)
$$

where $E$ is the electric field strength and $\epsilon_{p}$ the electrical permittivity of the particle. For most materials, $1<\epsilon_{p}<10$, relativity constant $K_{E}$ equal to $9 \times 10^{9}$, ion concentration $N_{i}$ is equal to $10^{13}$ ions.m $^{-3}$, and the mobility of ions in the air $Z_{i}$ has the value of $1.60 \times 10^{4} \mathrm{~m}^{2} \cdot \mathrm{V}^{-1} \cdot \mathrm{s}^{-1}$. The second factor in Eq. (6) indicates that the saturation charge is proportional to the surface area of the particle and to the electrostatic field strength. The results of this model have been validated by comparison with other models in the framework of the study conducted by Long and Yao (2010).

In the case of a liquid drop, the maximum charge is called the Rayleigh limit. When the mutual repulsion of electric charges within a droplet exceeds the confining force of the surface tension, the droplet shatters into smaller droplets. The limiting charge is given by Eq. (7):

$$
n_{L}=\left(\frac{2 \pi \gamma d_{p}^{3}}{K_{e} e^{2}}\right)^{\frac{1}{2}}
$$

where $\gamma$, is the surface tension of the droplet.

From this investigation based on dimensionless criteria and a literature review of EHD flow characterization by PIV or LDV, the following tracers were selected: cigarette smoke, incense smoke, oil smoke (cosmetic or synthetic oil) microballoons of $\mathrm{SiO}_{2}$, metallic particles of $\mathrm{TiO}_{2}$ and plastic particles of Expancel microspheres (EMS). 


\section{Materials and methods}

The main objective of this work was to compare tracer performance in an EHD flow. A needle/ring electrode configuration was developed to generate a corona discharge. In this configuration, velocity profiles obtained by PIV measurement were compared to those obtained by Pitot tube. As the measurement by Pitot tube took place in the absence of tracer, it was considered as a reference.

\subsection{Experimental device and measurement parameters}

An ionic wind was generated by a needle/ring configuration in a cylinder made of Plexiglas. The discharge electrode was a stainless steel needle of diameter $D_{n}=0.85 \mathrm{~mm}$ suspended by a Teflon rod placed on the top of the cylinder and aligned on the central axis of the ring. The inner and outer diameters of the cylinder were $D_{i n}=40 \mathrm{~mm}$ and $D_{e x}=50 \mathrm{~mm}$, respectively. The cathode was composed of an aluminum strip with a length $h$ of $8.5 \mathrm{~mm}$, adhered to the inner wall of the ring, at a distance $d$ of $40 \mathrm{~mm}$ from the electrode tip as shown in Fig. 1. This device generates an axisymmetric air jet whose velocity is governed by the voltage applied at the needle. This configuration works as an electrohydrodynamic gas pump in which the flow generated has an axial velocity due to the electric field.

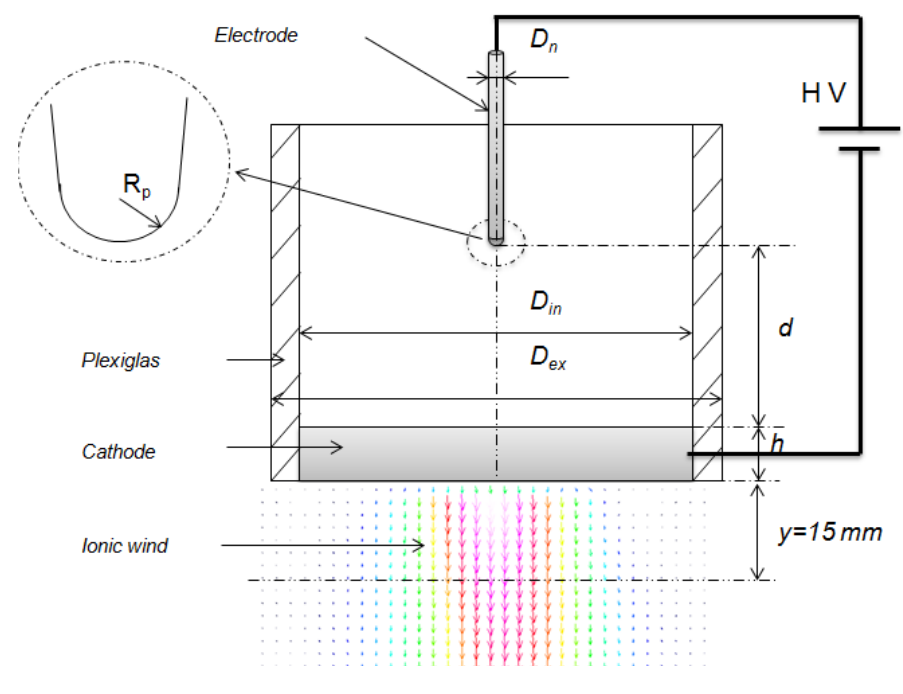

Fig. 1 Needle/ring corona discharge

\subsubsection{Velocity measurements}

The needle/ring configuration and the measurement system of the reference velocity with the Pitot tube and the PIV system are shown schematically in Fig. 2. The reference velocity was found by measuring the total pressure using a fine glass tube with a diameter of $1 \mathrm{~mm}$ positioned opposite to the jet. The choice of glass as a material for the Pitot tube avoids the electrostatic interaction of the jet as the ionic wind passes through the tube without distorting the measurement. The velocity measurements of the ionic wind with Pitot tube was used for the first time by Léger et al, (2001). The velocity profile was established at a welldefined position at $\mathrm{y}=15 \mathrm{~mm}$ from the output, and a voltage of $20 \mathrm{kV}$ was chosen to conduct experiments. These conditions allow for effective Pitot tube measurement and also helps overcome laser reflections from the aluminum cathode. The maximum air velocity ranged from $1.5 \mathrm{~m} . \mathrm{s}^{-1}$ to $2.5 \mathrm{~m} . \mathrm{s}^{-1}$. The measurement of velocity profile has not been performed in the inter-electrode gap. This is due to the 
cylindrical shape of the Plexiglas walls, which does not allow a view of the interior part of the cylinder by the PIV system.

The static pressure was measured at the same height by another tube in the atmosphere far from the ring to avoid disturbance. The horizontal profile according to the $r$ axis was obtained using the total pressure taken by the Pitot tube positioned by a micrometric displacement system. Both tubes were connected to a differential pressure sensor (Druck, LMP 5480 S/N 30086, France) that allows velocity measurement from 0 to $10 \mathrm{~m} . \mathrm{s}^{-1}$ with a tolerance of $0.25 \%$. For each point of the horizontal axis, the velocity was determined using the Bernoulli's equation from 30 samples at $1 \mathrm{~Hz}$. Therefore, the value of the axial velocity $U_{y}$ of the jet is deduced for each horizontal position traversed by the tube. The air density variation, $\rho_{\text {air }}$, is considered to be dependent on temperature $(T)$ and relative humidity $(R H)$ as follows (Eq. (8)):

$$
\rho_{\text {air }}=0.003483 \cdot\left(\frac{\left(1+X^{s}\right)}{1+1.6078 X^{s}}\right) \cdot\left(\frac{\left(1+P_{a t m}\right)}{T_{a m b}+273.15}\right)
$$

where $X^{s}$ represents the specific humidity, $P_{a t m}$ the atmospheric pressure, and $T_{a m b}$ the ambient temperature measured in the experimental box. The mean velocity at each point results from the acquisition during $30 \mathrm{~s}$ at $1 \mathrm{~Hz}$ frequency.

PIV measurement was conducted using a DualPower 20/65 Dantec Dynamics® system. A $532 \mathrm{~nm} \mathrm{Nd}$ : YAG laser with a pulse energy of $65 \mathrm{~mJ}$ was used to provide light during exposure, generating a laser sheet of $1 \mathrm{~mm}$ thickness through a transparent Plexiglas orifice. This laser sheet intersects the medium cylinder through the axis of the ring $(r=0 \mathrm{~mm})$. Double frame, double exposure images were recorded by a digital camera $\left(\right.$ CCD - HAMAMATSU ${ }^{\circledR}$ ), with a resolution of $2048 \times 2048$ pixels. Three hundred double frames per series of measurements at a frequency of $5 \mathrm{~Hz}$ were used to calculate the mean velocity. This number of frames is sufficient to reach a statically converged time-averaged measurement. The timing between two images (for each set of double frame images) was $100 \mu$ s depending on the bulk velocity. The observation area of the camera was a rectangle of $10 \mathrm{~cm} \times 8 \mathrm{~cm}$.

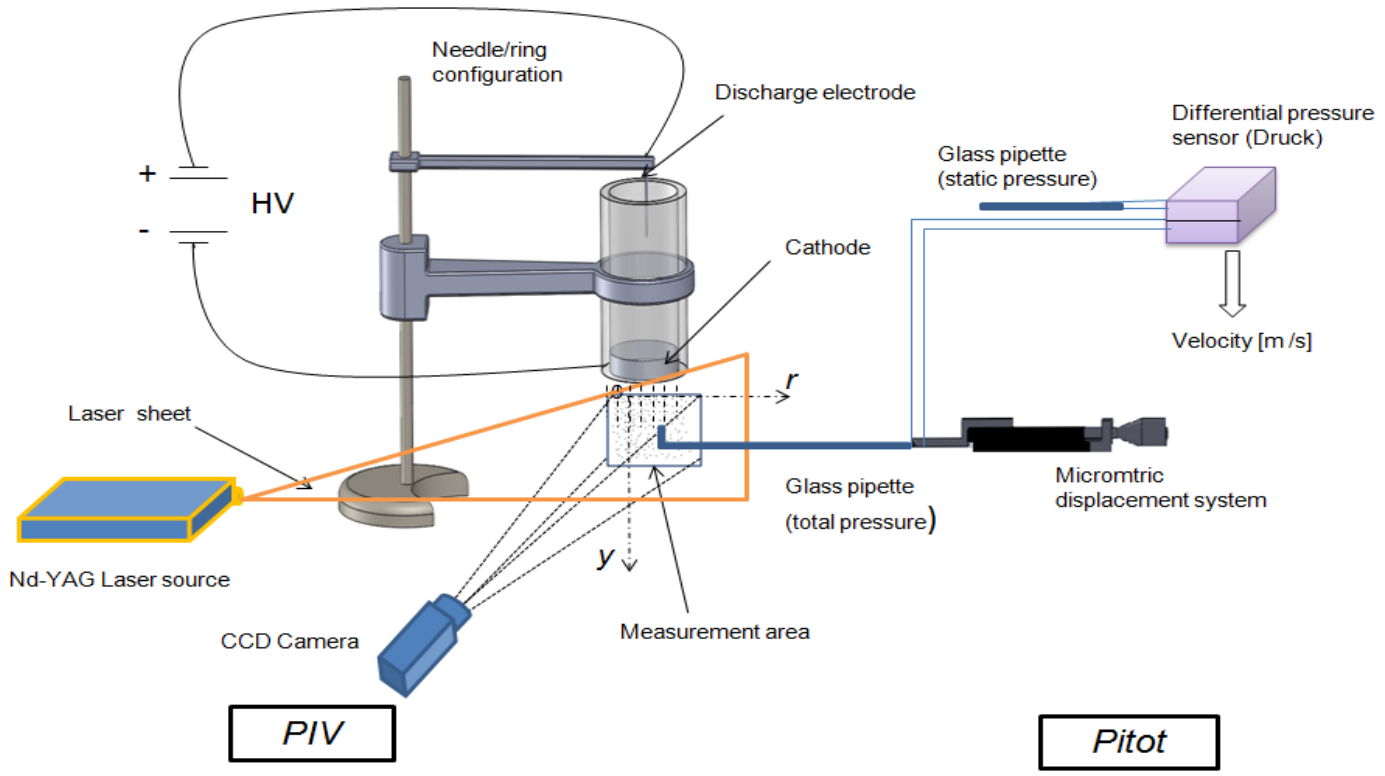

Fig. 2 Measurement by PIV and Pitot tube systems 
The image post-processing was performed with the PIV software "DynamicStudio". An adaptive correlation algorithm was used for processing and image analysis with variable window size (final size was $64 \times 64$ pixels) and $50 \%$ overlap.

\subsubsection{General scheme of the experiments}

A schematic diagram of the experimental apparatus is shown in Fig. 3. The seeding was performed in a closed box. The dimensions of the box were $120 \mathrm{~cm}$ x $70 \mathrm{~cm}$ x $50 \mathrm{~cm}$ with two sides of the box being transparent. The non-transparent inner walls were painted with matt black to prevent reflections of the laser light. The high voltage supply (HV) and the laser source (Dantec Dynamics ${ }^{\circledR}$ system) were outside the experimental box and the camera was placed perpendicular to the laser sheet facing the transparent box side. The camera and the laser generator were connected to the synchronization and image postprocessing computer. The data logger (AOIP ${ }^{\circledR}$, SA20) was also connected to the computer, to provide the sampling at the output of the HV generator, voltage measurements $(\mathrm{kV})$, current $(\mu \mathrm{A})$ and the voltage signal $(\Delta \mathrm{V})$ of the differential pressure sensor. In order to obtain information about the atmospheric conditions, a temperature and humidity sensor (ROTRONIC HYGROLOG ${ }^{\circledR}$, Switzerland) was placed near the box to limit the clutter inside the box. Specific measurements performed inside the box at the end of the experiments have confirmed that there was no significant variation between the inside and the outside of the box.

To control the particle concentration in the experimental box, an optical counter (Grimm: model G1.108) was used. The counter measures the optical intensity of light emitted by a particle. It records the particle number concentration on 8 channels. The tracer particle was sampled through an isokinetic probe, placed in the box, at an air-flow rate equal to $1.2 \mathrm{~L} \cdot \mathrm{min}^{-1}$.

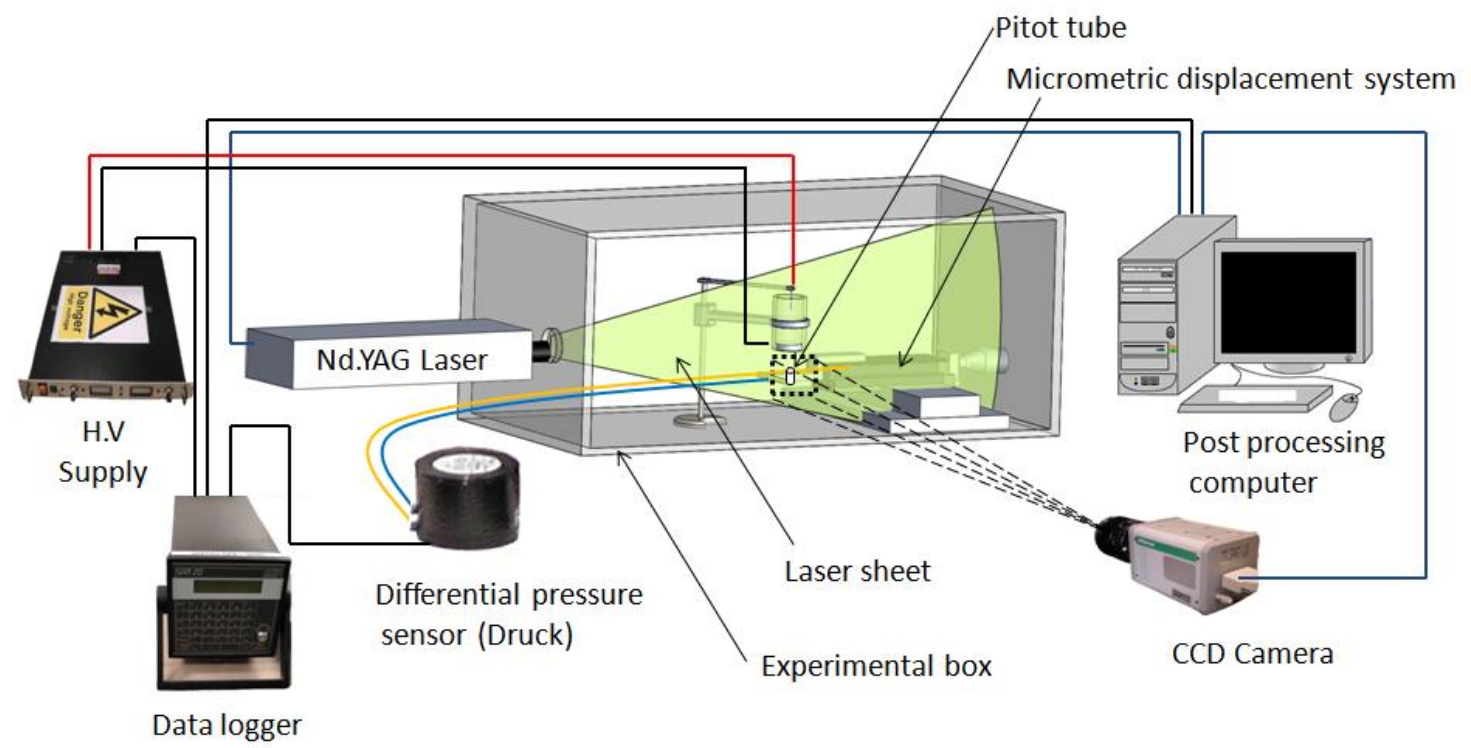

Fig. 3 General experimental device

\subsection{Tracer seeding characteristics}

Smoke from incense and cigarettes was produced by burning them directly inside the box for 3 to 4 min. This method provides sufficient particle density and a good correlation for a PIV post-processing algorithm. According to Becquermin et al. (2007), the average particle size of cigarette smoke is approximately $0.3 \mu \mathrm{m}$. The mean particle diameters of incense smoke and metallic particles of $\mathrm{TiO}_{2}$, measured by laser granulometry (Mastersizer, Malvern®), were found to be 0.8 and $0.7 \mu \mathrm{m}$, respectively. It was verified that their diameters remain constant over time measurements. The oil used to generate the seeding particles was a VDL-Smoke liquid (VDLSLHT5), which is composed of a mixture of glycol, mineral oils and demineralised water. The droplets were generated by heating to vaporization using an 
EXPELEC $^{\circledR}$ generator. The droplet size was measured by granulometry. As shown in Fig. 4, the droplet size depends on the measurement time. The droplet diameter increases from 0.6 to $4 \mu \mathrm{m}$ over a period of about 4 min resulting from the coalescence of droplets. According to Baron et al. (2008), droplets collide with each other due to Brownian motion and coalesce to form larger particles. Given the duration of seeding, it is assumed that the average diameter of the oil droplets was from $2 \mu \mathrm{m}$ to $3 \mu \mathrm{m}$ during the measurements. This oil is not dielectric and its diameter is largely higher than that of the oil used by Benard and Moreau (2010) $(0.3 \mu \mathrm{m})$.

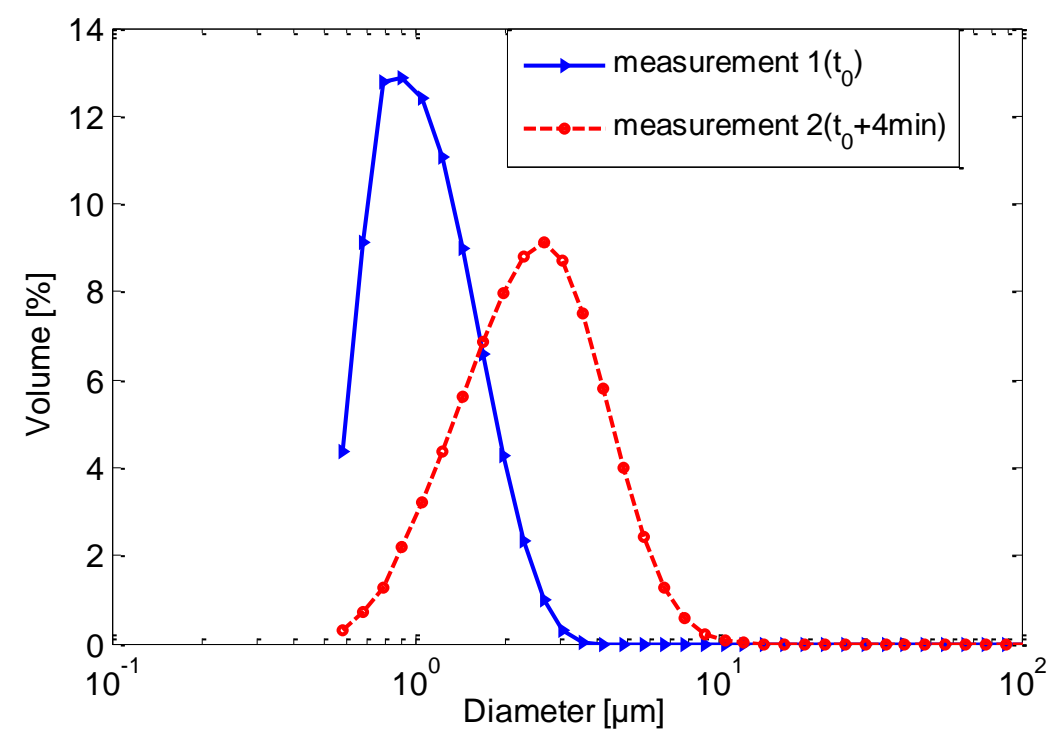

Fig. 4 Diameter size distribution of oil smoke

Solid particle seeding of $\mathrm{SiO}_{2}$ microballoons, $\mathrm{TiO}_{2}$ metallic particles and EMS particles was carried out by injecting a compressed air jet on a capsule that contained about one gram of the tracer sample. The air jet caused the dispersion of the particles throughout the box, so the initial conditions of the injection were the same for each tracer particle. According to the suppliers, the particle diameter of Expancel (EMS, Sweden)) is $15 \mu \mathrm{m}$ to $20 \mu \mathrm{m}$, and the particle density is $70 \mathrm{~kg} \cdot \mathrm{m}^{-3}$. For particles of titanium dioxide $\mathrm{TiO}_{2}$, the density is $4000 \mathrm{~kg} \cdot \mathrm{m}^{-3}$, while the $\mathrm{SiO}_{2}$ microballoons (Cospheric, USA) have a density of $1800 \mathrm{~kg} \cdot \mathrm{m}^{-3}$ and a diameter of $1 \mu \mathrm{m}$.

For the cigarette smoke particles, the values of the particle diameter reported in the literature range approximately from 0.3 to $1 \mu \mathrm{m}$ (Ping and Derek et al. (1996), Kocik et al. (2009) and Becquermin et al. (2007)). These variations in diameter could be explained by the coagulation of particles with time. According to Adam et al. (2009), as the particle diameter of cigarette smoke increases, the particle number decreases due to more time for particle coagulation.

The initial particle concentration was measured for each tracer tested. The concentration of particles with a diameter of $>0.3 \mu \mathrm{m}$ was similar, it ranged from $1.1 \times 10^{4}\left[\right.$ Particles. $\left.\mathrm{cm}^{-3}\right]$ to $2.6 \times 10^{4}\left[\right.$ Particles.cm $\left.{ }^{-3}\right]$

\section{Experimental results and discussion}

In order to evaluate the electric field strength, an analytical relationship based on Peek's law (White (1963)) was applied to the needle/ring corona discharge configuration as given in Eq. (9).

$$
E=3 \times 10^{6} \cdot m \cdot\left(\delta+0.0308 \sqrt{\frac{\delta}{R_{p}}}\right)
$$


where $E$ denotes the electric field strength at the surface, $m$ the surface roughness which is equal to 1 for smooth surfaces, $R_{p}$ the radius of the tip of the needle and $\delta$ the relative air density.

The field is intense very close to the electrode discharge at the needle tip (of the order of $10^{7} \mathrm{~V} \cdot \mathrm{m}^{-1}$ ). This value decreases rapidly towards the ring cathode. The dimensionless parameters are calculated in Table 2 for each tracer according to their physical characteristics and the highest value of the electric field strength. The maximum value of $E$, determined from Eq. (9), is used for the calculation of the parameter M. In the case of the Stokes number, the characteristic velocity $U_{c}$ is considered equal to the mean velocity of the air jet $\left(1.33 \mathrm{~m} . \mathrm{s}^{-1}\right)$ and the characteristic length $L_{c}$ equal to the inner diameter of the ring $(0.04 \mathrm{~m})$. The density and the viscosity of air are $1.25 \mathrm{~kg} . \mathrm{m}^{-3}$ and $1.85 \times 10^{-5} \mathrm{~Pa} . \mathrm{s}$, respectively. In order to evaluate the $\mathrm{M}$ parameter, the following constants are used:

Constant

Ion mobility $\left(\mathrm{Z}_{\mathrm{i}}\right)$

Average concentration of ions $\left(N_{i}\right)$

Elementary charge (c)

Electric field (E)

Air dielectric constant $(\varepsilon)$

Surface tension $(\gamma)$

Constant of relativity $(\mathrm{Ke})$

Cunningham factor

Charging time $(\mathrm{t})$

Dielectric constant of particles

$$
\begin{aligned}
& \text { Value } \\
& 1.5 \times 10^{-4} \mathrm{~m}^{2} \cdot \mathrm{V}^{-1} \cdot \mathrm{s}^{-1} \\
& 1 \times 10^{13} \mathrm{ions} \cdot \mathrm{m}^{-3} \\
& 1.6 \times 10^{-19} \mathrm{eV} \\
& 10^{7} \mathrm{~V} \cdot \mathrm{m}^{-1} \\
& 8.85 \times 10^{-12} \mathrm{~F} \cdot \mathrm{m}^{-1} \\
& 7.30 \times 10^{-2} \mathrm{~N} \cdot \mathrm{m}^{-1} \\
& 9 \times 10^{9} \\
& 1 \\
& 3 \mathrm{~s}
\end{aligned}
$$

\begin{tabular}{|c|c|c|c|c|c|}
\hline Tracer & $\begin{array}{c}\text { Diameter } \\
(\mu \mathrm{m})\end{array}$ & 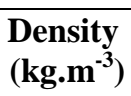 & $\begin{array}{c}\text { Stokes } \\
\text { number (St) }\end{array}$ & $\begin{array}{l}\text { Archimedes } \\
\text { number (Ar) }\end{array}$ & $\begin{array}{c}\text { Mobility ratio } \\
\text { (M) }\end{array}$ \\
\hline $\begin{array}{l}\text { Cigarette } \\
\text { smoke }\end{array}$ & $0.3-1$ & 1900 & $\begin{array}{c}6.9 \times 10^{-3}- \\
5.7 \times 10^{-2}\end{array}$ & $1.8 \times 10^{-6}-6.8 \times 10^{-5}$ & $228-20.5$ \\
\hline Incense smoke & 0.8 & 1100 & $2.2 \times 10^{-2}$ & $2 \times 10^{-5}$ & 27.9 \\
\hline Microballoons & 1 & 1800 & $5.4 \times 10^{-2}$ & $6.4 \times 10^{-5}$ & 17.4 \\
\hline EMS & 20 & 70 & $1.3 \times 10^{-2}$ & $2 \times 10^{-2}$ & $4.18 \times 10^{-2}$ \\
\hline Oil smoke & $0.6-4$ & 1360 & $\begin{array}{l}1.6 \times 10^{-2}- \\
5.7 \times 10^{-3}\end{array}$ & $1.1 \times 10^{-2}-3.1 \times 10^{-3}$ & $\begin{array}{l}8.8 \times 10^{-2}- \\
1.44 \times 10^{-2}\end{array}$ \\
\hline $\begin{array}{l}\mathrm{TiO}_{2} \text { metallic } \\
\text { particles }\end{array}$ & 0.7 & 4000 & $6.3 \times 10^{-2}$ & $4.9 \times 10^{-5}$ & 24.1 \\
\hline
\end{tabular}

Incense (3.7), Cigarette (2.6), EMS (5.4), $\mathrm{SiO}_{2}(4)$, Oil (88), $\mathrm{TiO}_{2}(110)$

Table 2. Dimensionless parameters St, Ar, and M

For all the tracers, the Stokes number $S t$ is never less than $10^{-2}$ except for cigarette smoke particles with a small diameter. The Archimedes number $A r$ is generally lower than $5.10^{-2}$ except for EMS particles. Regarding the mobility ratio $M$, it is very low for EMS and oil smoke particles whereas it is higher than 3 for $\mathrm{SiO}_{2}$ microballoons, $\mathrm{TiO}_{2}$ metallic particles and incense and cigarette smoke.

\subsection{Current-voltage characteristics}

When a strong electric field is applied between a high voltage and a grounded electrode in a gas medium, a corona discharge is formed by ionization of the gas molecules. Thus, the ions along the electric field transfer their momentum to the neutral molecules, which results in the so-called ionic wind or an electrohydrodynamically-induced gas flow. In the needle/ring configuration, the electrode configuration forms a symmetrical electric field distribution and a unidirectional gas flow can be generated. Fig. 5 shows the current variation $\mathrm{I}(\mu \mathrm{A})$ as a function of the applied voltage $(\mathrm{kV})$ in the absence of tracer in the 
air. The measured relative humidity $(\mathrm{RH})$ during this curve performance was $66 \%$. The curve is validated against the relationship $\left(\mathrm{I}=\mathrm{CV}\left(\mathrm{V}-\mathrm{V}_{0}\right)\right)$ and the constant $\mathrm{C}$ is equal to $2.5 \times 10^{-8} \mathrm{~A} . \mathrm{V}^{-2}$

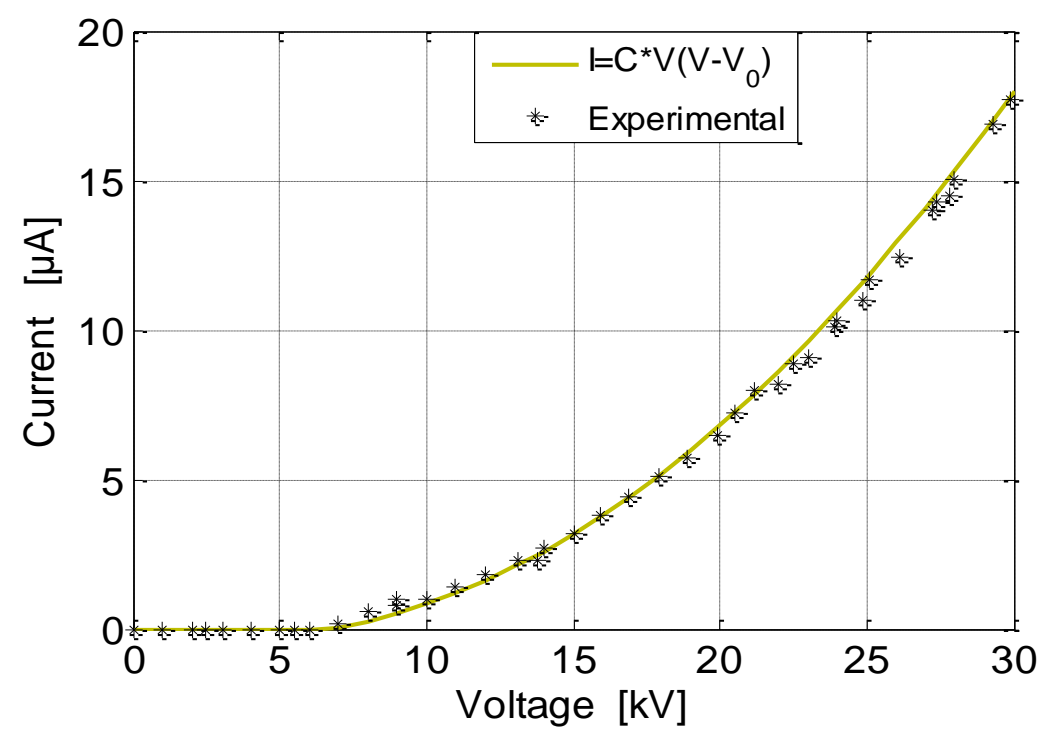

Fig. 5 Current-voltage characteristics (without tracer)

From a threshold voltage close to $5 \mathrm{kV}$, the ionization current is gradually triggered and increases with the applied voltage. For safety reasons, the voltage is limited to $30 \mathrm{kV}$.

Fig. 6 shows the current-voltage curves in the presence of different tracers in the air, performed at a constant humidity, $\mathrm{RH}$, of $66 \%$. It is clear that some kinds of tracer particles greatly influence the evolution of the electric current versus voltage. According to Hinds (1999), particle charging can occur through many mechanisms such as attachment of ions and static electrification. In this case, ion attachment is presumed to be the dominant charging mechanism, and two modes of ion attachment are possible; diffusion charging and field charging. Diffusion charging becomes predominant for particles with a diameter $<0.1 \mu \mathrm{m}$, even if an electric field is present. In this study, the seeding particles have a diameter greater than this value, so diffusion charging is negligible. Field charging occurs due to the electric field in the medium. The net charge acquired by the particle depends on the material.

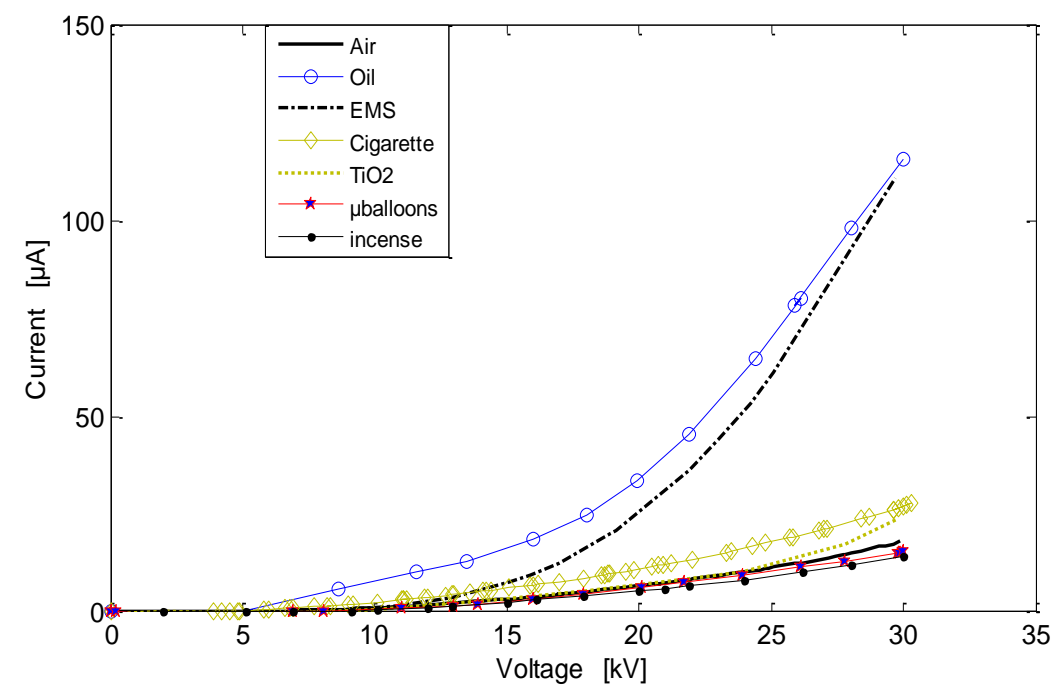


Fig. 6 Current-voltage characteristic curves with different tracers

In the voltage range considered, as shown in Fig. 6, the characteristic curves for the solid tracers $\left(\mathrm{SiO}_{2}\right.$ microballoons, $\mathrm{TiO}_{2}$ metallic particles and incense smoke) show a very slight difference with the curve obtained for air without tracers. This means that the effect of the tracers on the air characteristics is negligible. These results illustrate that the microballoons, $\mathrm{TiO}_{2}$ metallic particles and incense smoke tracers, are not affected by the electric field. Table 2 shows that tracers that are not affected by the electric field have a relatively high mobility ratio $(M>>3)$ because of their low electrical mobility.

It should be mentioned that no variation of $\mathrm{RH}$ and temperature was observed in the box for incense, cigarette smoke, $\mathrm{TiO} 2, \mathrm{EMS}$, and $\mathrm{SiO} 2$ micro balloons. We observed a slight variation of $\mathrm{RH}$ from $63 \%$ to $68 \%$ when seeding the box with the oil.

Conversely, in the case of EMS tracers, the current shows a very different behavior in comparison with the air without tracer where its values are very high for the highest voltage values. The EMS tracer is strongly influenced and the effect of the electric field is more prominent. From table 2, its tracer mobility ratio $\mathrm{M}$ is found to be of the order of $10^{-2}$. This value is very low because of the electrical mobility $K$, proportional to the electric charge carried by the particles, since the number of electric charge is proportional to the square of the diameter. During the seeding with EMS particles, we observed a strong particle deposition on both electrodes and the cylinder wall.

In the case of cigarette smoke, $M$ varies from 228 to 20. As shown in Fig. 6 , the current-voltage curve is slightly modified by cigarette smoke; this can be explained by a weak effect of the electric field due to increasing electrical mobility which is proportional to the diameter; this can modify the air characteristics in the box.

In the case of oil smoke, the current voltage characteristic curve shows a slight variation of the current in the voltage range 0 to $15 \mathrm{kV}$. The variation increases considerably from $15 \mathrm{kV}$ to $30 \mathrm{kV}$. One can explain that the oil which is composed of water and glycerin modifies the air characteristics in the box. As this oil is not dielectric but a conductive one and as the droplets diameter increases with the time, the oil particle becomes charged in its entire volume when it passes through the electric field (Jaworek et al. (2006)). It allows a large number of charges, about three orders of magnitude higher than a solid particle of the same diameter (Hinds (1999)). During the experiences, the seeding particles modify the humidity in the box of about $5 \%$ and a strong particles deposition on both electrodes and cylinder wall was observed.

From Eq. (9), the relative density of air influences the electric field strength. It is important to compare results concerning the velocity profiles in the same atmospheric conditions. Measurements for an applied voltage of $20 \mathrm{kV}$ and ambient conditions stabilized at a temperature of $20{ }^{\circ} \mathrm{C}$ and a relative humidity of $66 \%$ are further reported. It is also necessary to maintain the intensity of electric current during experiments. Fig. 7 shows the evolution of the current during a period without tracer measurements (air) and with seeding tracers. 


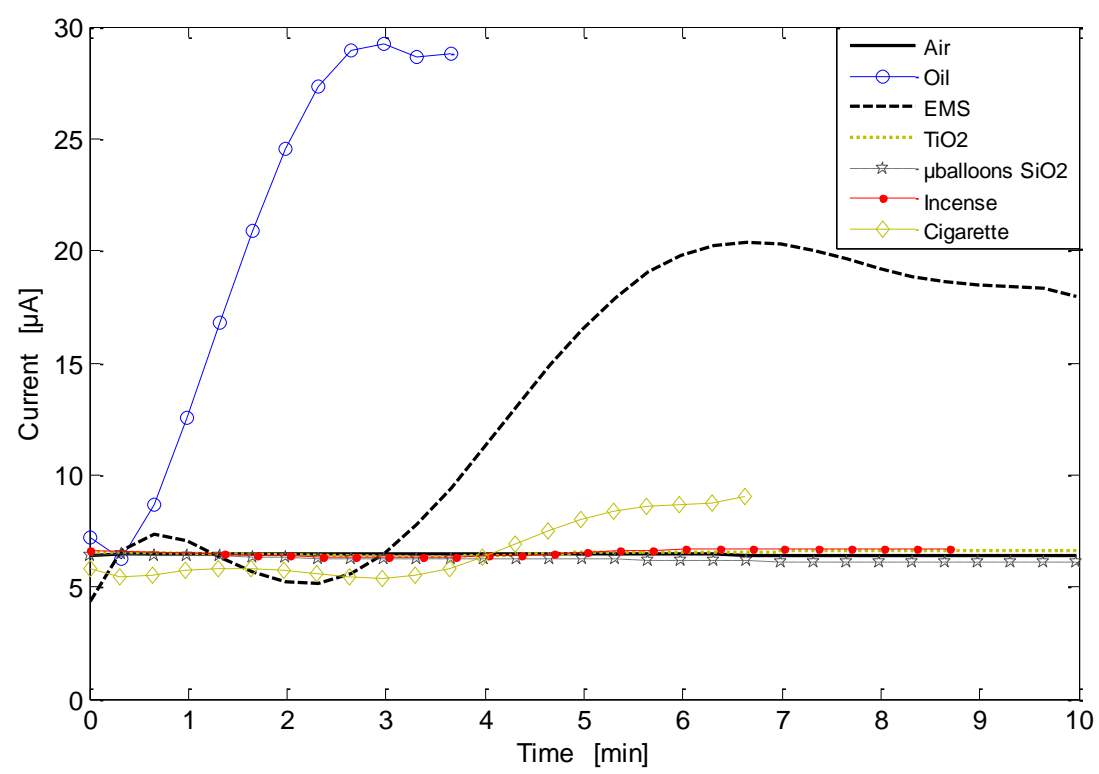

Fig. 7 Changes in current during PIV measurement without (air) and with seeding

Clearly, in the presence of the following tracer particles: $\mathrm{TiO}_{2}, \mathrm{SiO}_{2}$ microballoons and incense, the electric current is almost constant and similar to that without tracer. This means that during a period of time $(\mathrm{t}=10 \mathrm{~min})$, the presence of these particles does not affect the current. Therefore, PIV velocity and Pitot tube profiles can be easily compared. For the cigarette smoke tracer, the current is slightly modified and a significant difference in electric current can potentially affect PIV velocity profiles compared to those obtained by measuring with a Pitot tube. A very divergent evolution of current is seen with EMS and oil smoke tracers compared to that without a tracer. This phenomenon can be attributed to a strong charging particle mechanism that was explained earlier in this paper.

Because of the strong electric field strength near the needle tip (close to $10^{7} \mathrm{~V} . \mathrm{m}^{-1}$ ), particle charging is found to be prominent. The charging phenomenon is reduced significantly as the particle moves away from the needle until it becomes negligible. In addition to the lowest particle charging of $\mathrm{TiO}_{2}$ metallic particles, $\mathrm{SiO}_{2}$ microballoons and incense smoke tracers, the majority of the seeding particles pass far from the vicinity of the highest field corona region. As a result, the corresponding current is weakly affected.

An analysis of current versus time and voltage allows an a priori selection of several tracers. The results confirm that EMS, the used oil smoke and cigarette smoke tracers are not suitable for PIV seeding in EHD flow.

\subsection{PIV and Pitot comparison}

The PIV and Pitot tube measurements for $\mathrm{SiO}_{2}$ microballoons, $\mathrm{TiO}_{2}$ metallic particles and incense smoke tracers are presented in Figs. 8, 9 and 10. For each tracer, the velocity profiles obtained with PIV agree well with those measured by Pitot tube. These results are confirmed in other current/voltage configurations. It is also worth noting that the reproducibility of the results, based on 3 measurement operations, is satisfactory as depicted by the error bars in these figures. PIV profiles were obtained from an average of three profiles for each test. Thus the error is estimated at about $3 \%$. 


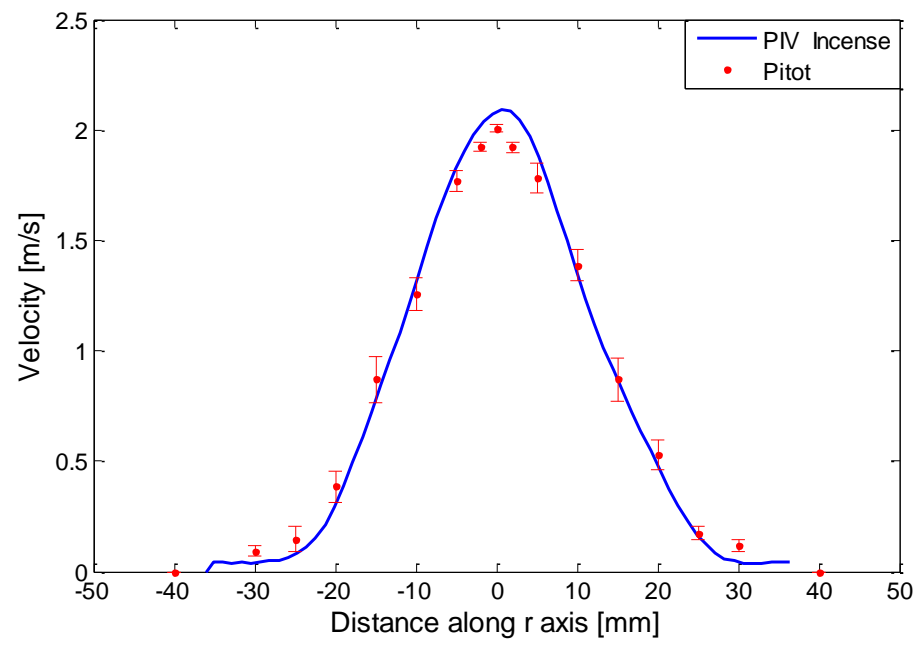

Fig. 8 Velocity profiles with PIV incense and Pitot measurement $(V=20 \mathrm{kV}, I=7.8 \mu \mathrm{A})$

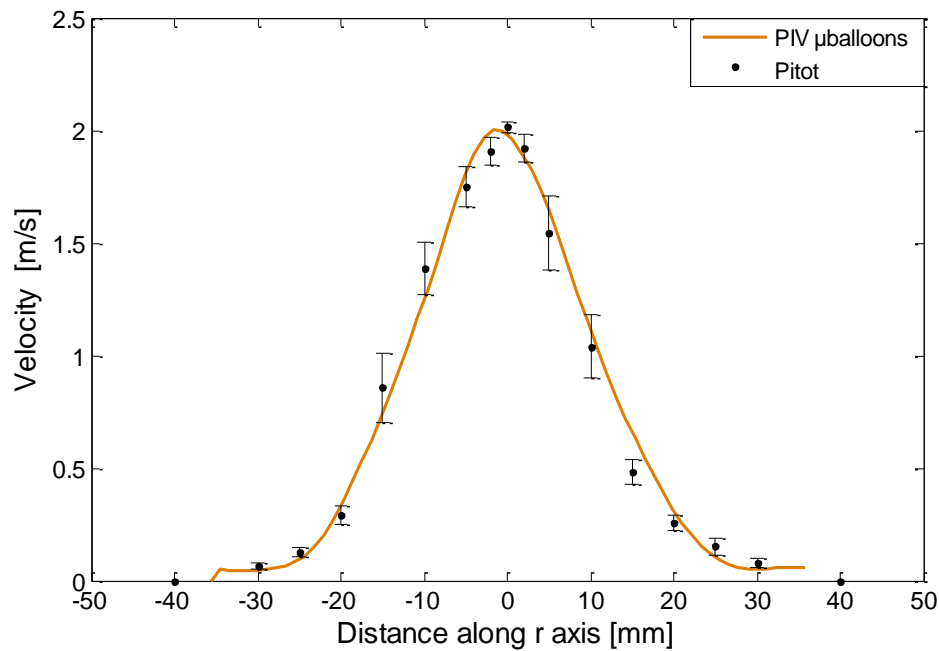

Fig. 9 Velocity profiles with PIV $\mathrm{SiO}_{2}$ microballoons and Pitot measurement $(V=20 k V, I=7.4 \mu \mathrm{A})$

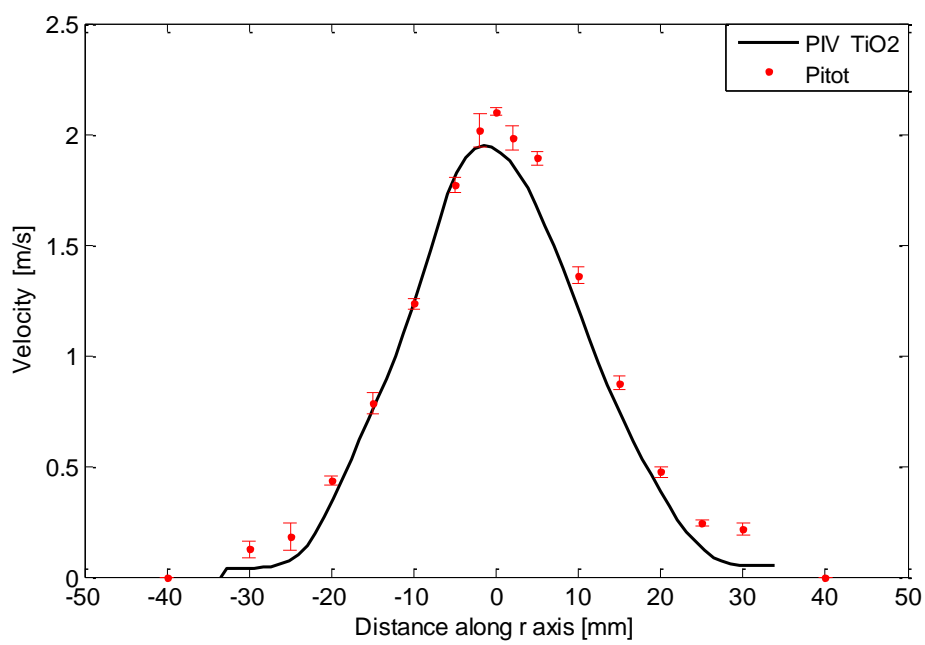

Fig. 10 Velocity profiles with PIV $\mathrm{TiO}_{2}$ metallic tracer and Pitot tube measurement $(V=20 \mathrm{kV}, I=6.4$ $\mu A)$ 
Among all the tracers tested, it is recommended to use the following: $\mathrm{SiO}_{2}$ microballoons, $\mathrm{TiO}_{2}$ metallic particles and incense smoke. They provide the best electrostatic behavior regarding the electric field and the best aerodynamic characteristics for tracking capability. Some experimental details report that $\mathrm{SiO}_{2}$ microballoon tracers provide better laser light reflection so more visibility on the images. This provides a good correlation with the post-processing software and low measurement uncertainty but these particles are still more expensive and should be recycled if possible. Incense smoke provides great facility of use and low cost. Thus, the use of $\mathrm{SiO}_{2}$ microballoon tracers and incense smoke can be advocated for PIV measurements in EHD flows.

\section{Conclusion}

In the first part of this study, a literature review was conducted, which enabled the criteria for selecting seeding particles to be identified. These criteria were presented in the form of dimensionless numbers: the Stokes number $(S t)$, Archimedes number $(A r)$, and mobility ratio $(M)$, taking into account the various parameters and physical characteristics of the tracer particles.

The objective of the second part was an experimental evaluation of tracers in a needle/ring corona discharge configuration. The behavior of tracers in PIV measurements was compared to the case in the absence of tracer, i.e. the Pitot measurement as a reference.

It was shown that, in order to compare the tracers and measurement techniques, the conditions and measurement parameters (current, voltage, humidity) have to be identical.

The choice of tracer particles was based on three criteria. The first, which consisted of comparing the current-voltage curves with and without tracers, highlighted the electrical charging of tracers. The second criterion was based on monitoring the electric current during each experiment to check its stability. Thirdly, a comparison of velocity profiles obtained using PIV and Pitot tube techniques was carried out. This showed that $\mathrm{SiO}_{2}$ microballoons, $\mathrm{TiO}_{2}$ metallic particles, incense and cigarette smoke are rarely or only slightly influenced by the electric field, while EMS particles and the used oil smoke are greatly affected. These carry too many electric charges and get high electrical mobility that makes them inappropriate for PIV in EHD flows, with $\mathrm{M}$ values $<<1$.

The dimensionless parameters calculated for each selected tracer have shown that relevant tracers are characterized by a value of $M$ greater than 3 and Stokes number smaller than $10^{-2}$. However, these characteristics are not sufficient as shown in the case of cigarette smoke, indicating that the parameter $\mathrm{M}$ seems to be not the only parameter to select the relevant tracers.

Among the particles tested, solid tracer particles of small diameter, like incense smoke, $\mathrm{SiO}_{2}$ microballoons and $\mathrm{TiO}_{2}$, can be recommended for PIV measurement in an EHD gaseous flow. This work constitutes a preliminary study and additional experiments will be carried out with tracers like dielectric oil, already recognized as being suitable for EHD flows. Such experiments would allow finding additional theoretical parameters able to predict if a particle is relevant or not for PIV measurements in EHD flows.

For researchers who would like to test other particles for seeding in EHD flow, it is recommended to perform a basic experiment that consists in measuring the changes in current with time. Current stability would mean that particles do not interact with the electric field.

\section{Acknowledgements}

The authors gratefully acknowledge the support of the Pays de Loire program for outstanding research in the field of energetics (PERLE2). The authors also wish to acknowledge Dr N. Zouzou (Institut PPrime, Poitiers, France) and Dr. C. Josset (Laboratoire de Thermocinétique de Nantes, France) for fruitful discussions. Authors also acknowledge Dr. E. Bardy (Grove City College, USA) for the careful reading of the paper. 


\section{References}

Adam T, McAughey J, McGrath C, Mocker C, Zimmerman R (2009) Simultaneous on-line size and chemical analysis of gas phase and particulate phase of cigarette mainstream smoke. Analytical and Bioanalytical Chemistry 394(4):1193-1203.

Allen PHG, Karayiannis TG (1995) Electrohydrodynamic enhancement of heat transfer and fluid flow. Journal: Heat Recovery Systems and CHP 15(5): 389-423.

Atten P, McCluskey FMJ, Lahjomri AC (1987) The electrodynamic origin of turbulence in electrostatic precipitators. IEEE Transactions on Industry Applications 23(4):705-711

Balagopal S, Go DB (2011) Counter-flow Ionic Wind for localized Hot Spot Cooling. ESA Annual Meeting on Electrostatics. IN: 46556. Proc. ESA Annual Meeting on Electrostatics

Baron R, Havet M, Solliec C, Pierrat D, Touchard G (2008) Numerical and Experimental Study of a Continuous Electrostatic Smoking Process. IEEE Transactions on Industry Applications 44(4):1052-1058

Becquermin HM, Bertholon JF, Attoui M, Roy F, Roy M, Dautzenberg B (2007) Tailles particulaires de la fumée produite par six différents types de cigarettes. Rev. Mal. Respir. 24:845-52.

Béquin P, Castor K, Scholten J (2003) Electric wind characterization in negative point-to-plane corona discharges in air. European Physics Journal AP 22:41-49

Burgmann S, Van der Schoot S, Asbach C, Wartmann J, Lindken R (2011) Analysis of tracer particles characteristics for micro PIV in wall-bounded gas flows. La houille blanche 4:55-61

Chang JS et al (2004) Optimization of seed-particle size and density used in the particle image velocimetry under corona discharge and non-thermal plasmas. Proc. 7 th Int. Conf. on Optical Particle Charactrization (Kyoto, Japan, August 2004), 435-440

Chang JS, Brocilo D, Urashima K, Dekowski J, Podlinski J, Mizeraczyk J, Touchard J (2005) On-set of EHD turbulence for cylinder in cross flow under corona discharges. Journal of Electrostatics 64: 69-573

Hinds WC (1999) Aerosol technology - properties, behavior, and measurement of airborne particles. John Wiley and Sons, NYC

IEEE-DEIS Technical Committee February (2003) Recommended International Standard for Dimensionless Parameters used in Electrohydrodynamics. IEEE Transaction on Dielectric and Electrical Insulation 10(1):3-6

Ikeda Y, Nishigaki M, Ippommatsu M, Hosokawa S, Nakajima, T (1994) Optimum seeding particles for successful LDV experiments. Proceedings of the 6th Symposium on Applications of Laser Techniques to Fluid Mechanics 11: 27-132

Jaworek A, Lackowski M, Krupa A, Czech T (2006) Electrostatic interaction of free EHD jets. Experiments in Fluids 40: 568-576

Joussot R, Leroy A, Weber R, Rabat H, Loyer S and Hong D, (2013) Plasma morphology and induced airflow characterization of a DBD actuator with serrated electrode. Journal of Physics D: Applied Physics, 46, doi:10.1088/0022-3727/46/12/125204

Kallio GA, Stock DE (1992) Interaction of electrostatic and fluid dynamic fields in wire-plate electrostatic precipitators. Journal of Fluid Mechanics 240:133-166

Kawamoto H, Umezu S (2008) Electrostatic micro-ozone fan that utilizes ionic wind induced in pin-toplate corona discharge system. Journal of Electrostatics 66:445-454 
Kocik M, Dokwsky J, Mizeraczyck J (2005) Particle precipitation efficiency in an electrostatic precipitator. Journal of Electrostatics 63:761-766

Kotsonis K and Ghaemi S (2011) Forcing mechanisms of dielectric barrier discharge plasma actuators at carrier frequency of $625 \mathrm{~Hz}$. Journal of Applied Physics 110:113301.1-113301.10

Léger L, Moreau E, Artana G (2001) Influence of a DC corona discharge on the air flow along an inclined flat plate. Journal of Electrostatics. 51-52: 300-306

Long Z, Yao Q (2010) Evaluation of various particle charging models for simulating particle dynamics in electrostatic precipitators. Journal of Aerosol Science 41:702-718

Melling A (1997) Tracer particles and seeding for particle image velocimetry. Measurement Science and Technology 8:1406-1416

Mizeraczyck J, Debowski J, Podlinski J, Kocik M, Ohkubo T, Kanazawa S (2003) Laser flow visualization and velocity fields by particle image velocimetry in an electrostatic precipitator model. Journal of Visualization 6:125-133

Moghaddam S, Kiger KT, Ohadi M (2006) Measurement of corona wind velocity and calculation of energy conversion efficiency for air-said heat transfer enhancement in compact heat exchangers. HVAC \& Research 12(1):57-68

Niewulis A, Podlinski J, Mizeraczyck J (2009) Electrohydrodynamic flow patterns in a narrow electrostatic precipitator with longitudinal or transverse wire electrode. Journal of Electrostatics 67:123127

Ould Ahmedou SA, Havet M (2009) Analysis of the EHD enhancement of heat transfer in a flat duct, IEEE Transactions on Dielectrics and Electrical Insulation 16(2):489-494

Paone N, Revel GM, Nino E (1996) Velocity measurement in high turbulent premixed flames by a PIV measurement system. Proc. 8th Int. Symp. on Application of Laser Techniques to Fluid Mechanics. Lisbon paper 3.4

Podlinski J, Dekowski J, Mizeraczyk J, Brocilo D,Urashima K, Chang J S (2005) EHD flow in a wide electrode spacing spike-plate electrostatic precipitator under positive polarity. Journal of Electrostatics 64:498-505

Ping C, Derek D (1996) In Situ Light Scattering Measurements of Mainstream and Sidestream Cigarette Smoke. Aerosol Science and Technology 24:85-101

Pol SU, Balakumar BJ (2012) Design consideration for large field particle image velocimetery (LF-PIV). Measurement Science and Technology 24, 2 doi:10.1088/0957-0233/24/2/025302

Reuss DL, Adrian RJ, Landreth CC, French DT, Fansler TD (1989) Instantaneous planar measurements of velocity and large-scale vorticity and strain rate in an engine using particle-image velocimetry, SAE paper 890616

Rickard M, Dunn-Rankin D, Weinberg F, Carleton F (2005) Characterization of ionic wind velocity. Journal of Electrostatics 63:711-716

Shimamoto S, Kazanawa S, Ohokubo T, Nomoto Y, Mizeraczyk J, Chang J (2004). Flow visualisation and current distribution for a corona radical shower reactor. Journal of Electrostatics 61:223-230 
Tarlet D, Bendicks C, Rolo C, Bordas R, Wunderlich B, Michaelis B, Thévenin D (2011) Gas flow measurements by 3D particle tracking velocimetry using coloured tracer particles. Flow, Turbulence and Combustion 1:110

Ullum T, Larsen PS, Özcan O (2004) Three-dimensional flow and turbulence structure in electrostatic precipitator by stereo PIV. Experiments in Fluids 36:91-99

Vincent JH (2007) Aerosol Sampling. Science, Standards, Instrumentation and Applications.

Wangnipparnto S, Tiansuwan J, Jiracheewanun S, Kiatsiriroat T, Wang CC (2002). Air side performance of thermosyphon heat exchanger in low Reynolds number region: with and without electric field. Energy Conversion and Management 43:1791-1800

White HJ (1963) Industrial Electrostatic Application. Addison-Wesley Publishing Company Inc.

Willert C, Jarius M (2002) Planar flow field measurements in atmospheric and pressurized combustion chamber. Experiments in Fluids 33:931-939

Zouzou N, Dramane B, Moreau E, Touchard G (2011) EHD Flow and Collection Efficiency of a DBD ESP in Wire-to-Plane and Plane-to-Plane Configurations. IEEE Transactions on Industry Applications. doi:10.1109/tia.2010.2091473 